\title{
Pop Culture, Twitter, and Study Abroad: Estonia as a Case Study
}

Joseph M. Ellis, Wingate University

ABSTRACT This article highlights a number of different pedagogical practices that can be used with study abroad programs, both classroom methods and out-of-class techniques. In this particular class-which focused on Estonia's Singing Revolution and included a 10-day trip abroad to Estonia-social media platforms like Twitter and Tumblr were frequently used to create collaboration among students. In addition, Estonian music and pop culture were studied, giving students a unique insight into a culture very foreign from their own. Although Estonia was the focus of this particular class, the results of these methods are generalizable to help others who lead study abroad programs and develop creative ways to foster interaction. This article also demonstrates why social media platforms are helpful to political scientists and the political science discipline more generally.

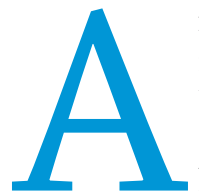

fter a semester-long course that focused on the Singing Revolution in May 2012, I led a group of 17 Wingate University undergraduate students to Estonia. Since 1978, Wingate University students have had the opportunity to travel abroad after a semester-long course study of a particular locale and topic. These trips are referred to as "W'International" around campus. As someone who spent time in the Baltics doing dissertation research and who has since become very interested in the Singing Revolution, I proposed a course study on Estonia that was accepted by the Wingate University International Studies committee. The difficulty I faced was that I had never taught a course solely on Estonia nor taken students abroad. I was perplexed at how best to offer meaningful instruction in the classroom while creating a fun and relaxing-but academic-experience while abroad.

This article describes the W'International process and highlights the respective teaching concepts I used to encourage participation and collaboration among my students, both in the classroom and abroad, further emphasizing the implications of such techniques for political scientists. In the classroom, current events, song, entertainment, and pop culture were prominent features of the seminar instruction as students were shown everything from Estonian television commercials to the story of a famous Estonian runway model. The article also shows how social media tools such as Twitter and Tumblr were useful pedagogical devices on study abroad trips. Because many students are already familiar with these social media platforms, professors can easily integrate these technologies into an academic curriculum that makes sense both to the student and the faculty member. Although Estonia was the focus of this class, the practices and tips listed

Joseph M. Ellis is an assistant professor of political science at Wingate University. He can be contacted at j.ellis@wingate.edu. here are useful to faculty who may lead groups anywhere in the world, or who teach a highly specialized seminar topic such as this.

\section{THE W'INTERNATIONAL PROGRAM}

In 1978, Wingate University, a small, liberal arts college located about 30 miles southeast of the large Charlotte-metro region in North Carolina (USA) initiated the first W'International program. The purpose of the program was to introduce Wingate students-many of whom were commuters who lived close to the rural campus-to international travel. The original 10-day program had just one seminar, was free, and was open to any student who wished to enroll. In addition, the seminars were called "W'International" because the trips were initially offered only during the "Winter" break. Currently, six seminars are offered each year. One seminar per semester costs each student around $\$ 200$, and all other seminars cost $\$ 850$, which is still a steeply discounted-and university subsidized-rate. For the faculty member the trip is free. For teaching the W'International course, faculty receive $\$ 2,000$ of overload pay and a small stipend for personal in-country expenses such as meals or taxi fare.

Each December professors interested in leading a W'International seminar must submit a course proposal to the Wingate International Studies Committee. The committee evaluates the proposals for academic purpose and strengths of the professors to teach a course on the particular topic and then lead the class abroad. Additional factors include the costs of the proposed seminar as well as having some "geographic diversity" among the trips offered. Often the trips were too "Europe-centric," and the committee wanted to branch out to locales in South America, Asia, and more infrequently, Africa.

On acceptance of a seminar proposal the faculty and students are notified and presentations are given in an assembly detailing 
what a student could expect in Estonia, or Spain, or Germany, for instance. W'International sign up day is now a core part of undergraduate culture. Students camp out the night before registration throughout the campus and then must be the first to form into the line when registration opens. The seminars are first come, first serve. When registration for a trip fills up students have the option of registering for another. Surprisingly, only about $40 \%$ of the student body actually participate in the W'International program. On satisfactory completion of the class portion of the seminar (grade of "C" or better) students will then journey to their destination.

The course I offered was "Estonia: How the Singing Revolution Ended the Communist Era." The two-hour credit course met once a week on Tuesday night. Seventeen students enrolled in the course, 14 women and three men. The course proceeded in three parts. First, a broad historical overview of Estonia was detailed were able to appreciate the song by both "seeing" and hearing it. The song was played a second time. This time students listened to the song in Estonian but read the lyrics in English. After the song was over we discussed what those words must have meant to Estonians, especially during the National Awakening period of the 1860 s. As Christopher Soper has noted, using music in the classroom is a good way to create a participatory or interactive classroom as students can think about political or social issues from a different perspective (Soper 2010, 364).

As the course progressed and students gained a firmer grasp on Estonian history and culture, Estonian pop culture was introduced. Pop culture has a way of making seemingly remote countries "mainstream" and can provide a connection for students that national history or politics might not. Countless professors use references to popular culture in the classroom, especially when dealing with topics or texts that are otherwise arcane (Centellas

\section{First, a broad historical overview of Estonia was detailed beginning with the thirteenth-century invasion by both German and Danish peoples. One of the themes we frequently discussed was Estonia's constant balance of "conquest and survival."}

beginning with the thirteenth-century invasion by both German and Danish peoples. One of the themes we frequently discussed was Estonia's constant balance of "conquest and survival." Second, the song festival and choral tradition was highlighted with special attention on the antecedents of the Singing Revolution. We traced the song festivals back to the original Laulupidu and read the poetry of Lydia Koidula. Third, Estonian independence was discussed, highlighting both pre- and post-Soviet independence periods. From the beginning of the course, the theme of the Singing Revolution was the undercurrent for the entire class. We had a campus-wide showing of The Singing Revolution documentary at the beginning of the semester. Roughly 150 students, faculty, and staff attended the screening.

\section{CLASS STRUCTURE: HOME AND ABROAD}

Several approaches were used to teach about Estonia and create discussion in the classroom. Each class began with a short video clip pertaining to Estonia. One class began with a news clip about a Narva teacher who was fired for speaking in Russian in an "official" capacity rather than in Estonian. Another clip included a guided tour of Old Town Tallinn by world traveler Rick Steves. The clips sometimes sparked conversation, and other times were used to simply quiet the class and get the students focused.

After the clip was shown the lecture began. Each lecture was approximately 40 minutes long and had a number of bulleted points that could be used for class discussion. The early lectures were very information "heavy" as most students did not have any previous knowledge of Estonia. These early lectures provided a broad historical sketch of Estonian history and culture. Most classes would also include either passing reference to or direct inclusion of song festival music. For example, for one class students were assigned to listen to the classic Mu Isamaa On Minu Arm and follow along to the Estonian lyrics in writing to try and train their ear to hearing Estonian words individually. While speaking the language was not requisite to taking the class students
2010, 562). One video clip was a promotional advertisement for an Estonian television station. The promo was called "The Estonians" and was set to the theme from the American television show The Simpsons. Students enjoyed this Estonian take on something quintessentially American. Another nod toward pop culture was the inclusion of a New York Times feature on Estonian supermodel Carmen Kass (Spindler 2001). The students were fascinated to find out that an Estonian was at one time one of the highest grossing models in the world. (One student also discovered to her delight that Carmen Kass dated Leonardo DiCaprio.) One other reference to pop culture included a discussion of the similarities between Lady Gaga and Estonian pop singer Kerli.

After the four-month in-class study was completed, we headed

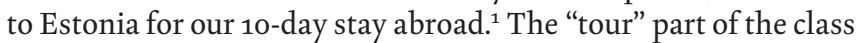
was a joint effort between myself, the director of international studies, and a travel agency located in Europe. While the faculty members advise on the basic details of where to go and what to visit, this is subject to review by the travel agency and the director. The agency scopes out the affordability of the ventureentrance fees, bus fees, tour guide costs-as well as all the major logistics. Well before departing, it is important to have someone in an international studies office who can handle passports and a host of other customs, liability, and emergency issues, in addition to general paperwork. This is crucial for taking groups from the United States to countries that require visas.

\section{SOCIAL MEDIA AND ITS USE ON STUDY ABROAD}

As the classroom portion of the class wound down we began to discuss ways to make the trip to Estonia intellectually stimulating without sacrificing the "fun" of traveling abroad. We decided to use various social media tools, including Twitter, Youtube, and Tumblr, to both promote our trip abroad and catalog it. The class was divided into three "social media" groups: a Twitter group, a blogger group, and a photography and videography group. Subsequently, the photography group was divided into five divisions: 
people, culture, buildings, nature, and transit. This division avoided several hundred photographs of the same few things. Each group-in real time-cataloged their trip while taking advantage of Estonia's abundant Wi-Fi connectivity. The Twitter group had five individual accounts that could be "followed" by anyone with a Twitter account, including their parents, friends, professors, or university administrators. The blogger group had individual blogging accounts through Tumblr that enabled them to write daily journal entries about the trip and post them for anyone to see. The photography group also used Tumblr to host their photos, and the videography groups used a combination of Vimeo, Youtube, and Twitter to host videos. Students began "tweeting" about the trip prior to departure and continued to do so throughout their journey. Because almost every student on the trip had a smartphone, most tweeted, took pictures and video, and blogged directly from their phones when they had access to Wi-Fi, which was available throughout the city and on the tour bus.

Those with Twitter accounts would make an observation or comment about a site we toured. This created interaction not only with the historical sites, but with others on the trip and the community. Twitter-a microblogging platform than enables users to communicate with others in "140 characters or less"-allows individuals to develop "unique networks in which learning occurs" (Veletsianos 2012, 337). For example, one student remarked on how beautiful Tartu was, prompting an official at Tartu University to reply to her post and welcome her to the city. Moreover, students could also use social media to connect to the class content, what one group of scholars has called "collaboration" (Grosseck and Holotescu 2008, 5). As one student tweeted: "Classroom lessons coming to life. Riigikogu, or the Estonian Parliament building!" [Italics added] Enclosed in the post was a snapshot of the class in front of Parliament (see appendix 1).

The students indicated that using Twitter was an effective way to communicate with one another as well as learn. On completion of the study abroad, several students were interviewed regarding their experiences using social media tools for the class. “... If I posted a picture, I was [then] able to verbally express my feelings on how in awe I was," said one respondent. "Then, I got to see my fellow classmate's ideas on the places we visited. I could reiterate some fun facts we learned on the trip, not only instilling that piece of information in my head, but educating my followers, too!" (e-mail interview respondent 1). Another student responded that without Twitter, "I would have looked over a lot of places and opportunities to learn about and document things" (e-mail interview respondent 2). And a third respondent remarked that documenting the activities on Twitter was like a "scrapbook of my experiences." As she further noted: "I am now able to look back at all of the posts and I have great memories from them" (e-mail interview respondent 3 ).

In addition to Twitter, two students wrote blogs about the trip, interspersing text and images in a readable and compelling narrative. The students titled and designed their blogs on their own (see appendix 2). Unlike tweeting, blogs are not restricted by character limits, and these can be written as a diary, chronicling the trip day by day. Like Twitter, however, students were able to blog about classroom lessons come to life. One example was a student who wrote about being able to attend the Song Festival grounds and see a "mini" song festival. She wrote: "Since ... song festivals were a main topic of discussion in our class, we refused to pass up the opportunity to attend. Once we arrived, we saw many Estonians were gathered in the amphitheater in special clothes that signified their community, just as we had observed in class. Their songs were absolutely beautiful" (student blog 1). Another student used her blog less as a diary and more of a promotional tool, listing facts, photos, and information and answering questions from followers. As she noted about Tartu's Gunpowder Cellar: "Fun Fact: This place is actually built underground in a hill. It was originally built to store actual gunpowder in Tartu, Estonia, and then turned into a restaurant/bar!" (student blog 2).

The third group was a photography and videography group, which itself is not necessarily social media, but can be used in such a capacity. By using picture-hosting sites such as Tumblr and Lockerz, the students included the class, university community, and student's families in learning about the trip. ${ }^{2}$ As previously mentioned, I divided the photography group into five divisions: people, culture, buildings, nature, and transit. After the trip division members were asked to send in their five or six best photos that were posted to a Tumblr account, which can be accessed and seen by anyone with the hyperlink. This posting was done partly for posterity's sake. I wanted students to have access to their photos for years to come and to share the trip with friends and family easily. Although students posted photos to their personal Facebook and Twitter accounts, often access to those accounts is limited to fellow users, friends, or followers. Another reason to use something like a Tumblr account is from a promotional and marketing standpoint if you want to plan another trip in the future. Distributing a link is relatively easy and, as faculty, it can be an efficient way to "sell" a class or trip.

In addition to photographers, three students did videography and then used programs like Youtube or Vimeo to host the video. Videography is now quite easy with the proliferation of smartphones, as video capabilities on these phones are quite good. One particular moment that many students recorded was a small song festival on our last night in Tallinn. Capturing sound for this beautiful music and the motion of the dancing and swaying was a priceless moment for the students, and one they captured in the first person. Videographers on the trip also captured a dance recital at a Tartu shopping center, an impromptu street concert in Old Town Tallinn, and a FC Flora soccer match.

\section{IMPLICATIONS FOR TEACHING POLITICAL SCIENCE AND BEYOND}

Teaching a semester-long case study on Estonia has been the most focused and detailed lecturing of my career. Moreover, teaching about Estonia-one of my research passions-has been rewarding. What lessons from this experience might be helpful to other political scientists or educators in other disciplines? Does Estonia make for a special case that lends itself to such interactive pedagogy, or can this approach be applied across the board? Four telling things have come out of this experience.

First, Estonia is a great conduit to teaching about the fall of the Soviet Union. In classes where I have taught about the Singing Revolution before, students are struck by the courage of people and the use of song to protest. When teaching about the fall of the Soviet Union the lecture normally begins with the Berlin Wall. The Berlin Wall has an iconic place within the public's memory, and it is possible a student's parents or grandparents could roughly explain what the collapse of the wall meant. But beyond the German experience, most students are both unaware and unfamiliar 
with what it meant for the Soviet Union to "fall" and for the subsequent satellite states to topple also. Estonia is an excellent case study to contrast, for example, the violent end to Romanian communism but also the problems of independence in Lithuania, where people died in those transition years.

Second, Estonia offers a great test of "civic education." One of the ongoing struggles political scientists face is trying to be both social scientists and "relevant" to the outside world. This includes encouraging our students to participate actively in politics and their community. In a study done on civic education among political scientists, Hunter and Brisbin, Jr. (2003) noted that "overall, faculty ... tended to believe that teaching civic responsibility was a fairly important goal" (762). The story of Estonia is no doubt inspirational, but it is also instructive, especially for those political scientists who try to encourage political activism among students. Estimates of participation in the Singing Revolution have ranged from roughly one-quarter to one-third of the entire population of Estonia. True, Estonia's movement toward independence was helped by a weakened Soviet Union, but Estonians from various political groupings, regions, and ages also committed themselves to change. The Estonian case demonstrates that people devoted to a cause can make a difference. What is also powerful about the Estonian experience-and this applies to Latvia and Lithuania as well-were the remarkable number of young people who helped shape the country. (Most notably one can point to the then 32-year-old Prime Minister Mart Laar as case in point.) I always discuss this point with my students: you do not have to be a certain age to make a difference politically.

Third, there has been a continued emphasis in education on creating "collaborative classrooms" and encouraging active learning. This trend includes the active participation of students both inside the classroom and outside of it. Collaborative classrooms do not preclude a traditional lecture environment; however, active participation does encourage students to take ownership of their educational experience. The reason for grouping the students into social media groups was to promote a collaborative endeavor among them. For example, Twitter allows any user to "follow" another user. So the group that is tweeting both before and during the trip are encouraging and supporting each other through directed tweets and following each other. A study from Junco, Heibergert, and Loken (2011) demonstrated that not only can social media platforms like Twitter foster academic dialogue, but it also creates interpersonal relationships among students that a traditional classroom setting cannot always capture (126). In addition, they observed that Twitter assignments "promoted active learning ... by helping students relate the course material to their own experiences both inside and outside the classroom" (128).

Lastly, the class shows how effective social media can be used inside and outside the classroom. Several recent studies (Grosseck and Holotescu 2008; Veletsianos 2012; Young 2010) have researched the pedagogical usefulness of social media tools. For this course social media use was a great success-it created a "conversation" about Estonia among the students and the community and never detracted from their learning. One of the underexplored dimensions of student social media use is whether the learning emanates not so much from the content of the tweet, or blog, or photograph, but rather in the actual participatory act and engaging with others.

\section{CONCLUSION}

This class allowed for some creative uses of pedagogy, specifically using song to teach about history and politics, the inclusion of pop culture as an educational tool, and most importantly, the use of social media such as Twitter and blogs for an interactive learning experience. Moreover, the topic of the Singing Revolution was a great hook for attracting students to the class, and it also served as the backdrop to understanding social protest and unrest in a crumbling Soviet Union. It is hoped that this article has provided some insights for scholars not only interested in post-Soviet and Baltic politics, but also those who are interested in using forms of social media within the context of study aboard. I hope it also encourages academics to see leading study abroad as rewarding experiences that not only enrich the lives of the students but also improve the teaching done by faculty in environments beyond the traditional classroom.

\section{ACKNOWLEDGMENTS}

The author thanks Wingate University, the Wingate International Studies committee, Jennifer Armentrout, and the students who trusted him enough to take them many thousands of miles overseas to Estonia. In particular, he would like to thank Wingate undergraduates Sarah Ellen Carpenter, Emma Harnett, Grace Krauser, Sarah Mitchell, Ragan Riddle, and Savannah Whitaker for their contributions to this article. Any mistakes or misinterpretations herein are the sole responsibility of the author.

\section{NOTES}

1. Two of the 10 days of this trip were spent traveling, with a connection through Germany, then Helsinki, and across the ferry to Tallinn.

2. Pictures from the trip can be found here: http://estoniaellis.tumblr.com/

\section{REFEREN CES}

Centellas, Miguel. 2010. "Pop Culture in the Classroom: American Idol, Karl Marx, and Alexis de Tocqueville." PS: Political Science and Politics 43 (3): 561-65.

E-mail Interview. Respondent 1. 14 January 2013.

E-mail Interview. Respondent 2. 8 January 2013.

E-mail Interview. Respondent 3. 16 January 2013

Grosseck, Gabriela, and Carmen Holotescu. 2008. "Can We Use Twitter for Educational Activities?" Presented at the 4th International Scientific Conference on eLearning and Software for Education. Bucharest, Hungary, April 17-18.

Hunter, Susan, and Richard Brisbin, Jr. 2003. "Civic Education and Political Science: A Survey of Practices.” PS: Political Science and Politics 36 (4): 759-63.

Junco, Reynol, Greg Heibergert, and Eric Loken. 2011. "The Effect of Twitter on College Student Engagement and Grades." Journal of Computer Assisted Learning 27 (1): 119-32.

Soper, Christopher. 2010. "Rock and Roll Will Never Die: Using Music to Engage Students in the Study of Political Science." PS: Political Science and Politics 43 (2): $363-67$.

Spindler, Chelsea. 2001. "I'm the Richest Girl in Estonia." New York Times, August 19. http://www.nytimes.com/2001/o8/19/magazine/i-m-the-richest-girl-in -estonia.html?pagewanted $=$ all\&src $=$ pm

Veletsianos, George. 2012. "Higher Education Scholars' Participation and Practices on Twitter." Journal of Computer Assisted Learning 28 (1): 336-49.

Young, Jeffrey. 2010. "Teaching with Twitter: Not for the Faint of Heart." The Chronicle of Higher Education 56 (1): 9-12. 


\section{APPENDIX 1: Using Twitter in Estonia}

Ragan Riddle EstoniaRagan

Classroom lessons coming to life. Riigikogu, or the Estonian

Parliament Building! lockerzcom/s/210170508

回 Hide photo \& Reply 27 Retweet $\star$ Favorite *.. More

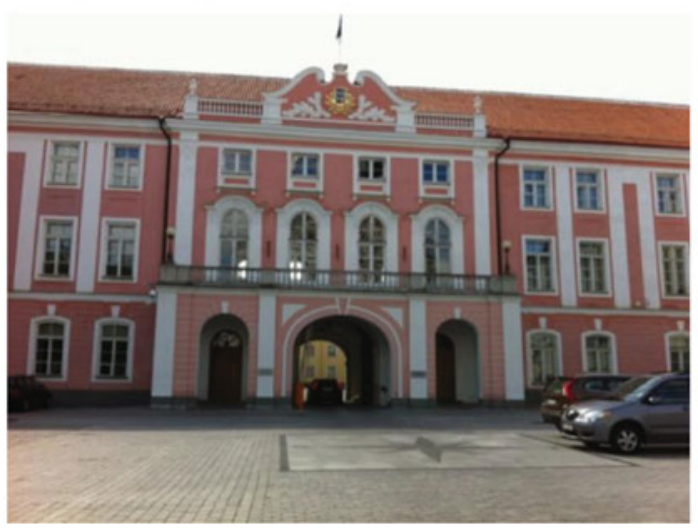

⿷ Lockerz

Flag this media

11:09 a.m. - May 19, 2012 - Details

Sarah Mitchell Estoniasarah

My favorite moment by far during the stay in Estonia. Watching

Estonians sing at the festival grounds. \#unbelievable

pic twitter.com/fQXDNFPq

囬 Hide photo \& Reply tz Retweet $\star$ Favorite $\cdots$ More

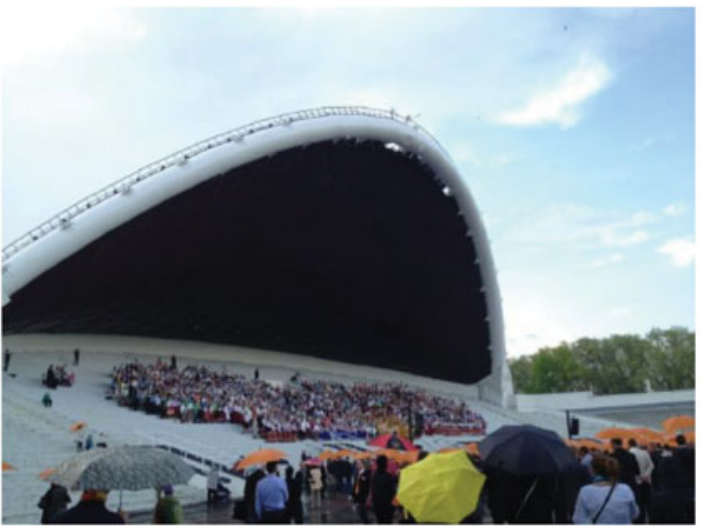

1

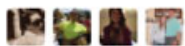

(Color online.) 